\title{
Avances de la Medicina Veterinaria en la Amazonía Peruana
}

\section{Advances in Veterinany Medecine in the Preuvian Amazon}

\author{
Puicón, Victor ${ }^{10000-0003-2532-2551]}$ \\ ${ }^{1}$ Universidad Nacional de San Martín, Tarapoto, Perú
}

\section{Editorial} vhpuiconeunsm.edu.pe

La Región San Martín posee una alta riqueza de flora y fauna silvestre, una belleza paisajística singular, una variedad de relieves geográficos y una gran diversidad cultural. La producción pecuaria consiste principalmente de ganado bovino, porcino y avícola (1). Además, la acuicultura es un campo que se ha ido desarrollando progresivamente debido al financiamiento de diversas entidades del Estado y en colaboración con la banca privada, este panorama en el desarrollo de la ganadería, la riqueza en fauna silvestre y el auge en el sector acuícola, genera el reto de la formación de médicos veterinarios egresados altamente capacitados y a la vanguardia del desarrollo tecnológico productivo y sanitario que está emergiendo en los últimos tiempos.

La carrera de Medicina Veterinaria en la Universidad Nacional de San Martin, inició en el año 1994, como la carrera profesional de Medicina Veterinaria y Zootecnia, la cual fue aprobada e implementada en el año 2008. Desde aquel entonces, nuestro compromiso como Escuela de Medicina Veterinaria, es formar a los futuros médicos veterinarios con la calidad académica exigente, la investigación formativa, y la capacidad de producción científica, rasgos que son esenciales y definitorios en la identidad universitaria contemporánea (2).

El fin de la Universidad, no sólo se restringe a lo académico y a lo científico, sino también al aspecto de Proyección Social, por lo que la preocupación de nuestra comunidad veterinaria es vincular a los estudiantes y egresados con la realidad de nuestra región y país. Por lo tanto, se suma a este esfuerzo en conjunto de autoridades, docentes, estudiantes y egresados, la realización de la presente Revista de Veterinaria y Zootecnia Amazónica, la cual estamos muy seguros que contribuirá con el desarrollo de la excelente calidad científica de nuestra Amazonía Peruana.

MV. MSc. Víctor Puicón Niño de Guzmán Investigador Calificado RENACYT-CONCYTEC Editor de la Revista Facultad de Ciencias Agrarias Universidad Nacional de San Martín 
Vol. 1, Núm. 1, jul-dic, 2021

\section{Referencias bibliográficas}

1. MINAGRI. Anuario Producción Pecuaria y Avícola 2000-2014. 2015.

2. Parra Moreno C. Apuntes sobre la investigación formativa. Educ y Educ [Internet]. 2004;(7):55-77. Disponible en: https://www.redalyc.org/pdf/834/83400707.pdf 